\title{
Knowledge, Attitude and Oral Hygiene Practices among Medical Practitioners in Delta State, Nigeria
}

\author{
Mabel O. Etetafia1, Ese Anibor², Efe J. Ojigho-Jaiyeoba², Martins Obaroefe² \\ ${ }^{1}$ Department of Oral and Maxillofacial Surgery, Delta State University Teaching Hospital, Oghara, Nigeria \\ ${ }^{2}$ Department of Human Anatomy and Cell Biology, Delta State University, Abraka, Abraka, Nigeria \\ Email: obaromartins@yahoo.com
}

How to cite this paper: Etetafia, M.O., Anibor, E., Ojigho-Jaiyeoba, E.J. and Obaroefe, M. (2018) Knowledge, Attitude and Oral Hygiene Practices among Medical Practitioners in Delta State, Nigeria. Open Journal of Applied Sciences, 8, 576-585. https://doi.org/10.4236/ojapps.2018.812046

Received: November 3, 2018

Accepted: December 17, 2018

Published: December 20, 2018

Copyright $\odot 2018$ by authors and Scientific Research Publishing Inc. This work is licensed under the Creative Commons Attribution International License (CC BY 4.0).

http://creativecommons.org/licenses/by/4.0/

\begin{abstract}
Background: The knowledge of good oral hygiene is of paramount importance for the technical knowhow to keep one's mouth clean and free from periodontal diseases. Thus, one's attitude towards oral hygiene directly affects the oral health status. Aims: The study aimed at evaluating the knowledge, attitude and oral hygiene practices among medical practitioners in Delta State, Nigeria. The research also aimed at determining the effect of sex on knowledge, attitude and oral hygiene practices. Methodology: This study was an observational cross sectional study. Purposive sampling technique was employed. A total of a hundred and twenty-three health care providers were assessed with a structured questionnaire. Ethical approval was obtained from the Ethics and Research Committee in the Department of Human Anatomy and Cell Biology, Delta State University, Abraka, Nigeria. Data was analyzed using SPSS version 18.0 package. Descriptive statistics was analyzed using simple frequency percentages distribution and association between categorical variables and sex was done using a chi-square test. Significance was accepted at $\mathrm{p}<0.05$. Result: Findings from the study present $76.0 \%$ males and $24.0 \%$ females in the studied population. Five categories of health care providers were assessed, $63.0 \%$ of respondents were medical officers, $21.0 \%$ were consultants, and $10.0 \%$ were residents, while $6.0 \%$ were house officers. The results showed that $43.9 \%$ of the participants brushed their teeth once daily, $54.5 \%$ twice daily while $1.6 \%$ thrice daily. Respondents were asked the last time they visited a dentist. Out of the 123 participants, $37.4 \%$ never visited, $20.3 \%$ claimed six months ago, $13.0 \%$ visited a year ago, $10.6 \%$ two years ago and $19.40 \%$ visited more than two years ago. It also shows percentage distribution of variant types of last treatment, $19.5 \%$ had extraction, $10.6 \%$ had filling, and $33.3 \%$ had scaling and polishing while $36.6 \%$ had other types of dental treatment. The study revealed that the majority of the respondents
\end{abstract}


(93.5\%) had a positive attitude towards oral health. A total of $91.9 \%$ of the participants had knowledge of oral hygiene, while $8.1 \%$ had no idea of oral hygiene. More than half of the respondent (57.2\%) agreed and strongly agreed that oral hygiene knowledge in medical schools was adequate while $35.0 \%$ disagreed and strongly disagreed. There was no significant association ( $p>0.05$ ) between frequency of daily teeth brushing, last dental visit, variant treatments and sex. Conclusion: Findings from this study showed that the majority of the participants had an adequate knowledge on proper oral hygiene care and they had a positive attitude towards oral health. Being health care providers, the adequate knowledge and positive attitude could have a positive impact on the patients.

\section{Keywords}

Knowledge, Attitudes, Oral Hygiene, Delta State, Medical Practitioner

\section{Introduction}

According to Braimoh et al., 2006 [1], general health is not accessed only by the absence of diseases. The majority of oral diseases are closely related to lifestyles, which means that a change in behavior is required to decrease oral diseases [1]. According to Peterson 2003 [2], Oral health is a vital component of general health. A number of risk factors such as tobacco smoking, alcohol, and nutritional status are related to several oral diseases (Watt, 2005; Phillips and Aryan, 2017 [3] [4]).

Sharda and Shetty, 2011 [5] stipulated that oral diseases have a significant influence on an individual's social life and chronic diseases, for example periodontitis leads to tooth loss, which in turn impacts the individual physically, emotionally and psychologically, which then affects the quality of life. Oral hygiene is the most significant factor towards prevention of oral diseases [2]. Marmot and Bell, 2011 [6] stated that the concept, importance, and practice of oral hygiene are expected to be easily understood by all literate members of a population [6]. They further reported that an individual perception towards oral health generally affects the oral health behavior.

Multiple studies have demonstrated that the sources for oral health knowledge are mass media, health professionals and related literatures [1]-[7]. Studies have also shown that there is a direct relationship between increased knowledge of oral hygiene and better oral health (Woolgrove et al., 1987 [8]). In Libya Africa Naveenkumar et al., 2016 [9], found that respondents from his study had poor knowledge towards oral health. Oral health knowledge acquired by an individual is the basis of its attitudes towards oral health [9].

A study carried out among teachers in Benin City Nigeria showed that they were pessimistic towards oral health and so they had poor oral health practices [10]. Another study carried out among medical health practitioners and students in Ile Ife Nigeria, reported a negative attitude towards oral health (Sede and Ehizele, 
2015) [11]. The previous study carried out in Ile Ife were similar to that of Vincent et al., 2017 [12] among antenatal clinic attendees in south southern Nigeria [12].

Several studies have been carried out on knowledge and attitude towards oral health hygiene but there is dearth of knowledge on the area where the study was conducted, hence this study assessed knowledge, attitude and oral hygiene practices among medical practitioners in Delta State, Nigeria. This study also aimed at describing the association between knowledge, attitudes, oral hygiene practices and sex. Findings will be highly useful in developing health promotion activities which includes education, intervention programs and campaigns aimed at changing pessimistic attitudes and practices towards oral health.

\section{Methodology}

This observational cross sectional study was done at the Conference Centre of the Petroleum Training Institute, Effurun, Nigeria. Effurun in Delta State is the capital town of Uvwie Local Government Area, Nigeria and an access into Delta State. The study area was chosen because of a gathering of medical practitioners held at Petroleum Training Institute. Purposive sampling technique was employed for this research. A total of a hundred and twenty three Medical Practitioners were investigated while attending Continuing Medical Education Workshop in June, 2016. Information on socio-demographic characteristics and categorical variables were obtained using a questionnaire designed for the study. Information on knowledge, attitudes and oral hygiene practices were extracted from the questionnaire. The categorical variables were knowledge, attitude and oral hygiene practices among medical practitioners. Prior to the conduct of this study, ethical approval was obtained from the Ethics Committee in the Department of Human Anatomy and Cell Biology, Delta State University, Abraka, Nigeria. Voluntary informed consent was also gotten from participants. The data was analyzed using SPSS version 18.0 package. Descriptive statistics was analyzed using percentages. Association between categorical variables and sex was done using a chi-square test. Significance was accepted at $\mathrm{p}<0.05$.

\section{Results}

Figure 1 presents $24.0 \%$ females and $76.0 \%$ males in the studied population. Findings from this investigation (Figure 2) showed that $36.0 \%$ of respondents worked in private clinics, $15.0 \%$ each practiced in central and general hospitals, $9.0 \%$ in the teaching hospital and $25.0 \%$ practiced in other health centers. Among respondents (Figure 3), the majority (63.0\%) were medical officers while house officers constituted the minority (6.0\%). Findings as indicated in Figure 4 showed medical officers formed the majority $(79.0 \%)$ of the respondents while the specialist consultants constituted $21.1 \%$. Out of the consultants, $6.0 \%$ specialized in obstetrics and gynecology, $4.0 \%$ in general surgery, $4.0 \%$ were physicians, $2.0 \%$ were orthopedic surgeons, while mental health/Psychiatrist, oral and maxillofacial surgeons, anesthetist, family medicine physicians and plastic surge- 
ons were $1.0 \%$ each. Figure 5 presents $43.9 \%$ of participants who brushed their teeth once daily, $54.5 \%$ twice daily while $1.60 \%$ thrice daily. The last time of visit to the dentist is shown in Figure 6. From the respondents, 37.4\% had never visited, $20.3 \%$ claimed six months ago, $13 \%$ visited a year ago, $10.6 \%$ two years ago and $19.40 \%$ visited more than two years ago. Figure 7 shows the percentage distribution of last dental treatment; in which $19.5 \%$ had dental extractions, $10.6 \%$ had filings, $33.3 \%$ had scaling and polishing and $36.6 \%$ had other forms of dental treatment. Figure 8 shows that most of the respondents $93.50 \%$ had a positive attitude while $6.50 \%$ had negative attitude towards oral hygiene practices.

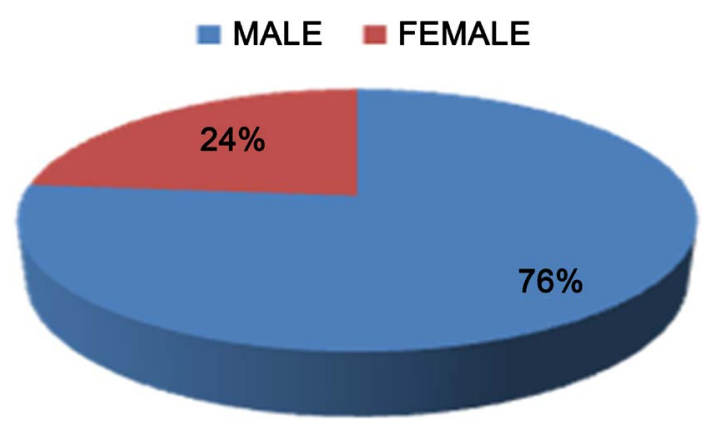

Figure 1. Gender distribution of respondents.

PRIVATE HEALTH CLINIC $\square$ GENERAL HOSPITAL $\square$ CENTRAL HOSPITAL

TEACHING HOSPITAL OTHERS

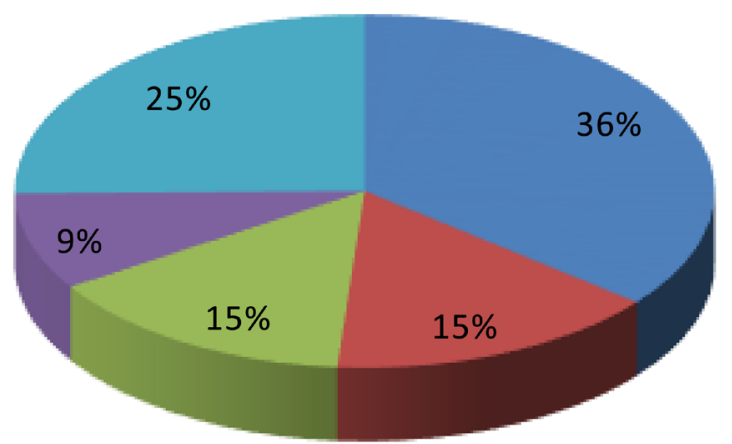

Figure 2. Percentage distribution of practice centre.

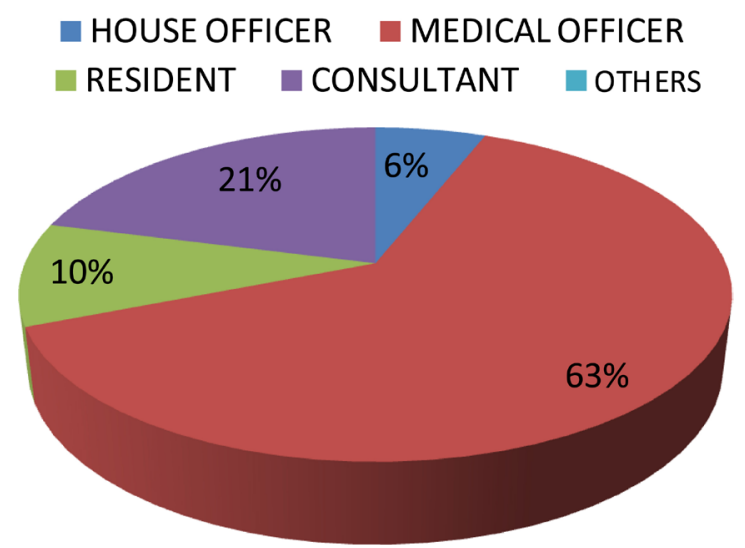

Figure 3. Category of medical practitioners. 


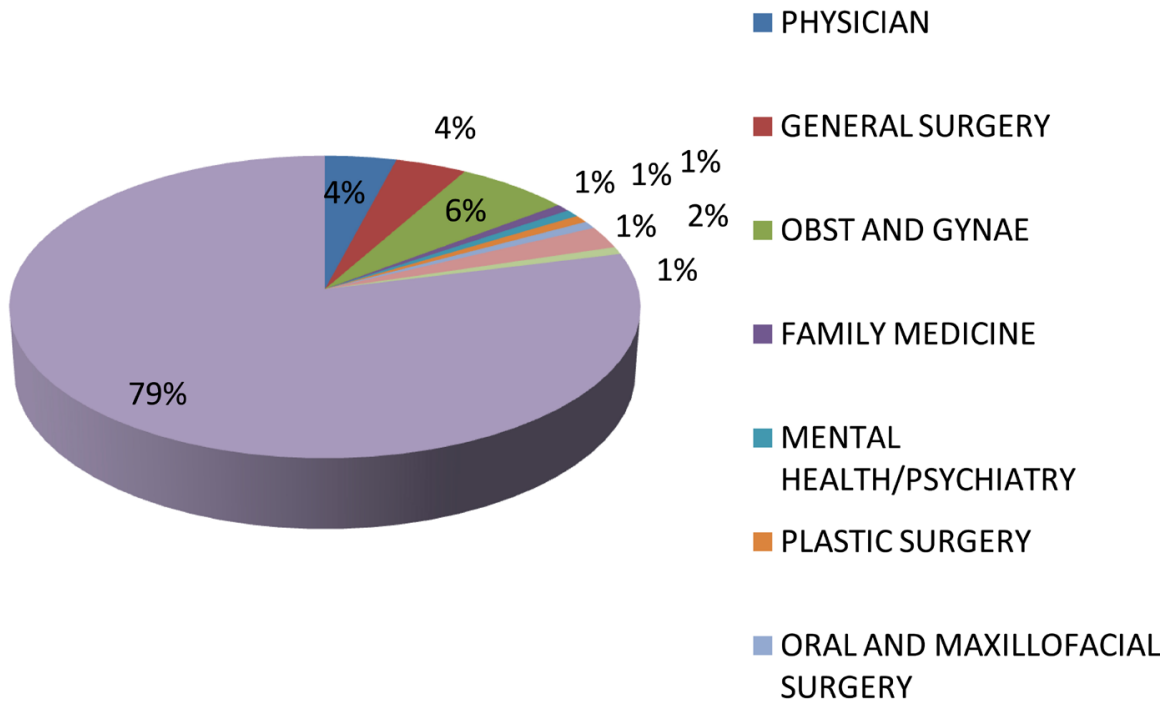

Figure 4. Specialty of respondents.

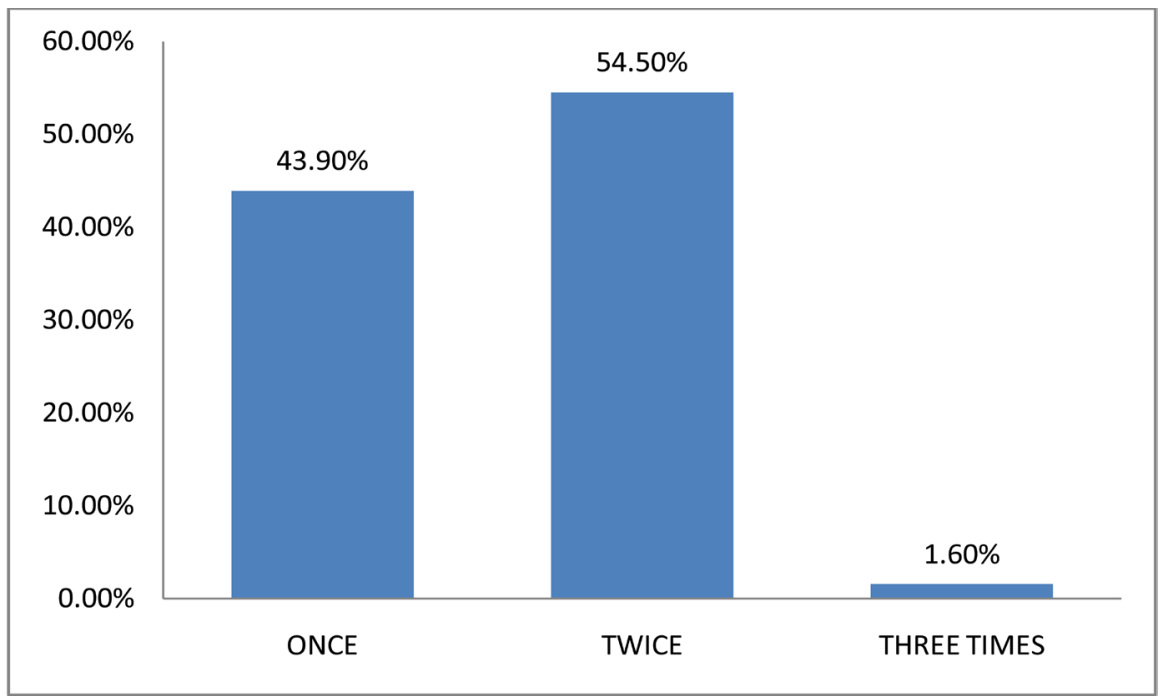

Figure 5. Percentage distribution of daily teeth brushing.

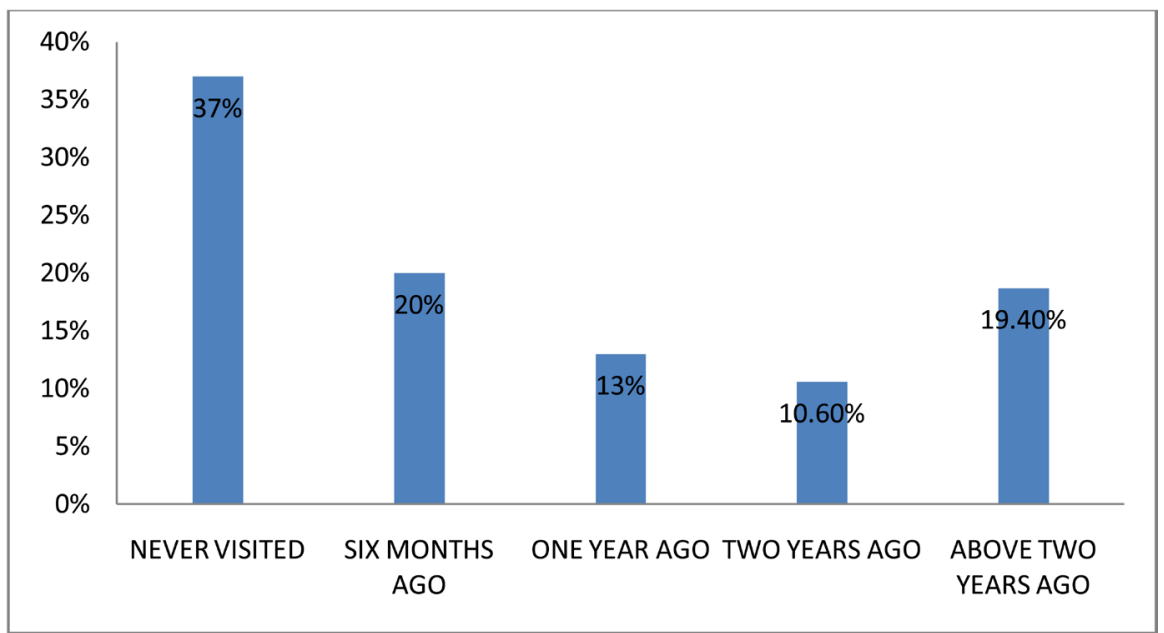

Figure 6. Percentage distribution of last dental visit. 
Respondents were also assessed on their perception towards oral health. The majority of the respondents had a positive attitude (93.5\%) towards oral health. Findings from Table 1 showed that $91.9 \%$ of participants had knowledge on oral hygiene while $8.1 \%$ had no idea of oral hygiene. Table 2 depicts that $47.2 \%$ agreed and strongly agreed that oral hygiene knowledge was adequate in medical schools while $35.0 \%$ disagreed and strongly disagreed that the oral hygiene knowledge they had adequate knowledge in medical schools. Table 3 showed the association between sex and frequency of tooth brushing. Findings depicts that there was no significant association at $p>0.05$. Table 4 shows the test of association between sex and frequency of tooth brushing. Findings showed that there

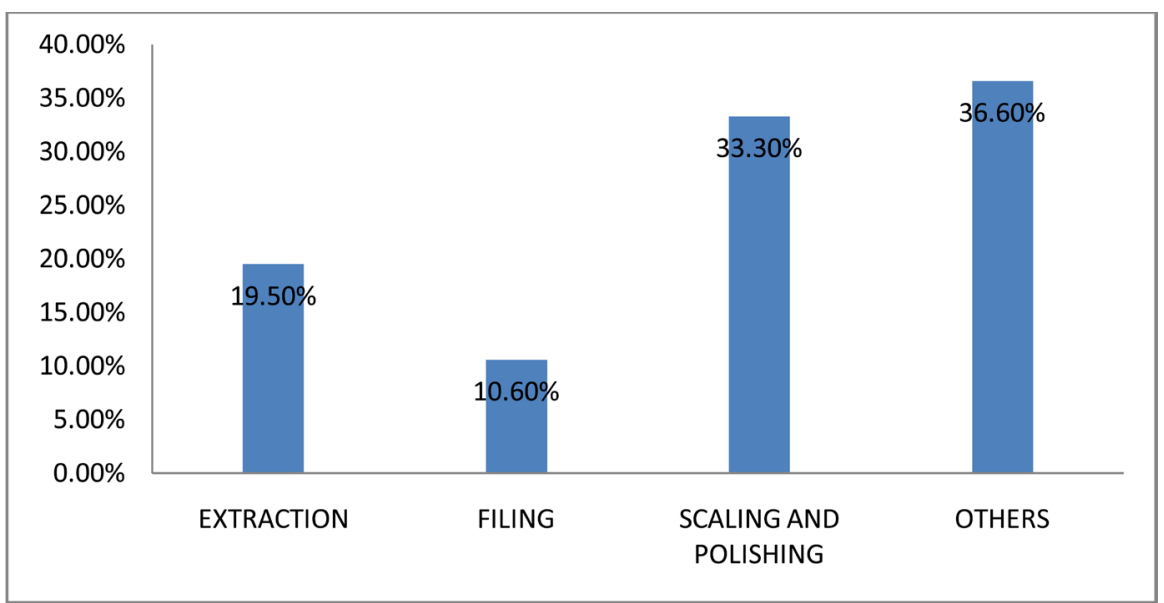

Figure 7. Percentage distribution of variant treatment.

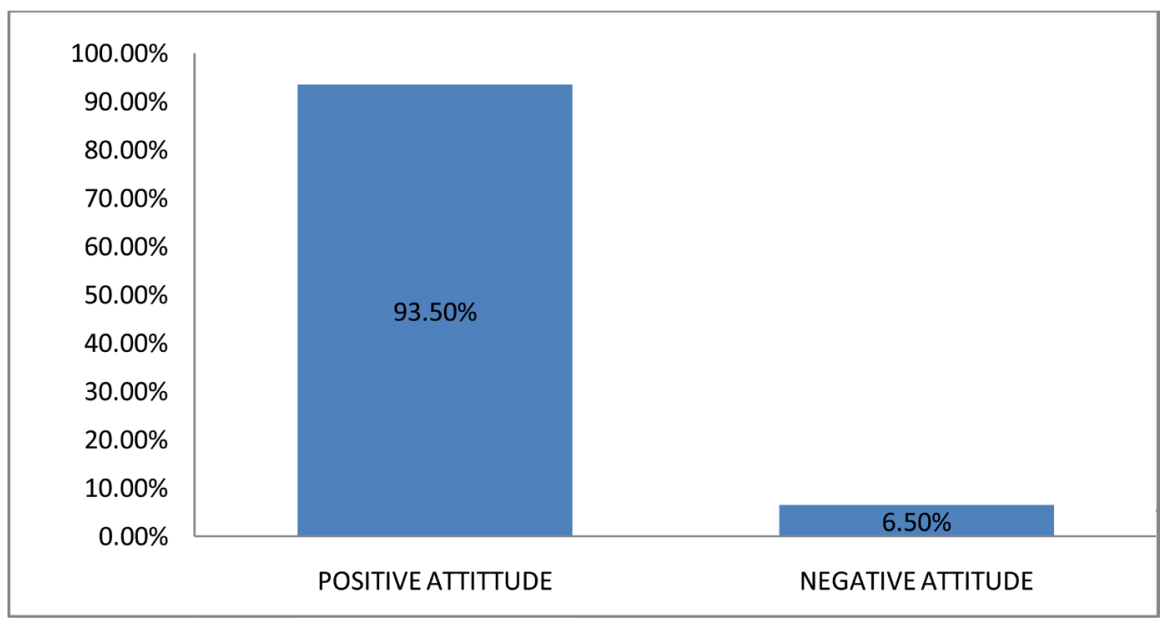

Figure 8. Attitudes towards oral health.

Table 1. Knowledge on oral hygiene.

\begin{tabular}{ccc}
\hline & Frequency & Percent \\
\hline YES & 113 & 91.9 \\
NO & 10 & 8.1 \\
Total & 123 & 100.0 \\
\hline
\end{tabular}


Table 2. Knowledge of oral hygiene is adequate in medical school.

\begin{tabular}{ccc}
\hline & Frequency & Percent \\
\hline Strongly Disagree & 14 & 11.4 \\
Disagree & 29 & 23.6 \\
Neutral & 22 & 17.9 \\
Agree & 38 & 30.9 \\
Strongly Agree & 20 & 16.3 \\
Total & 123 & 100 \\
\hline
\end{tabular}

Table 3. Frequency of daily teeth brushing and sex.

\begin{tabular}{cccc}
\hline \multirow{2}{*}{ Frequency of daily teeth brushing } & \multicolumn{2}{c}{ Sex } & \multirow{2}{*}{ Total } \\
\cline { 2 - 3 } & Male & Female & \\
\hline Once & $43(79.6 \%)$ & $11(20.4 \%)$ & $54(100 \%)$ \\
Twice & $49(73.1 \%)$ & $18(26.9 \%)$ & $67(100 \%)$ \\
Three times & $2(100.0 \%)$ & $0(0 \%)$ & $2(100.0 \%)$ \\
Total & $\mathbf{9 4 ( 7 6 . 4 \% ) )}$ & $\mathbf{2 9 ( 2 3 . 6 \% )}$ & $\mathbf{1 2 3 ( 1 0 0 . 0 \% )}$ \\
\hline
\end{tabular}

$\mathrm{df}=2$, Chi-square $=0.515$.

Table 4. Last visit to dentist and sex.

\begin{tabular}{cccc}
\hline \multirow{2}{*}{ Last visit to dentist } & \multicolumn{2}{c}{ Sex } & \multirow{2}{*}{ Total } \\
\cline { 2 - 3 } & Male & Female & \\
\hline Never visited & $35(76.1 \%)$ & $11(23.9 \%)$ & $46(100 \%)$ \\
Six months ago & $20(80.0 \%)$ & $5(20.0 \%)$ & $25(100 \%)$ \\
One year ago & $12(75.0 \%)$ & $4(25.0 \%)$ & $16(100 \%)$ \\
Two years ago & $10(76.9 \%)$ & $3(23.1 \%)$ & $13(100 \%)$ \\
Above two years ago & $17(73.9 \%)$ & $6(26.1 \%)$ & $23(100 \%)$ \\
Total & $\mathbf{9 4 ( 7 6 . 4 \% )}$ & $\mathbf{2 9 ( 2 3 . 6 \% )}$ & $\mathbf{1 2 3}(100 \%)$ \\
\hline
\end{tabular}

$\mathrm{df}=4$, Chi-Square $=0.991$.

Table 5. Variant treatment and sex.

\begin{tabular}{cccc}
\hline \multirow{2}{*}{ Last treatment } & \multicolumn{2}{c}{ Sex } & \multirow{2}{*}{ Total } \\
\cline { 2 - 3 } & Male & Female & \\
\hline Extraction & $20(83.3 \%)$ & $4(16.7 \%)$ & $24(100 \%)$ \\
Filling & $10(76.9 \%)$ & $3(23.1 \%)$ & $13(100 \%)$ \\
Scaling and polishing & $32(78.0 \%$ & $9(22.0 \%)$ & $41(100 \%)$ \\
Others & $32(71.1 \%)$ & $13(28.9 \%)$ & $45(100 \%)$ \\
Total & $\mathbf{9 4 ( 7 6 . 4 \% )}$ & $\mathbf{2 9 ( 2 3 . 6 )}$ & $\mathbf{1 2 3 ( 1 0 0 . 0 \% )}$ \\
\hline
\end{tabular}

$\mathrm{df}=3$, Chi-Square $=0.705$.

was no association at $\mathrm{p}>0.05$. Table 5 reported no significant association $(\mathrm{p}>$ 0.05 ) between variant treatment and sex. 


\section{Discussion}

The essence of the knowledge of proper oral healthcare management cannot be overemphasized in modern medicine, as attitude towards oral health are usually intertwine with the conditions of the oral cavity. In modern medical practices, different healthcare providers see a variety of patients in their daily clinical duties and can therefore have major influence on the knowledge and attitudes of the patients. The foregoing suggested an assessment of the knowledge, attitude and oral hygiene practices of various healthcare providers towards oral hygiene in Delta State, keeping abreast the role expected to be played by them to ensure proper oral hygiene care for patients in hospitals and the State as a whole to influence a behavioural change in the society. This present study is an assessment of the knowledge, attitude and oral hygiene practices of medical practitioners in Delta State, Nigeria.

Findings from this study showed that the majority of the respondents brushed twice a day. The results were in accordance with Akpata and Vincent et al., 2017 [13] [14] among secondary school children in Nigeria and among antenatal clinic attendees in public secondary health facilities in Benin City, Nigeria. Most of the participants from this investigation brushed at least once a day. The result is in accordance with Arun et al., 2010 [15] who reported once daily brushing to be $30.3 \%$, from their study among medical students in India.

Attitude towards oral hygiene were assessed among respondents. The findings from this investigation showed that most of them never visited the dentist. These findings at variant with Sharda and Shetty, 2008 [16] who reported that regular visit to dentist were found among care providers in India. Our finding partly concurs with Akpata, 2014 [13], who reported that almost half of the respondents never visited a dentist, $14.6 \%$ visited among secondary school children in Nigeria. This finding also partly agrees with Arun et al., 2010 [15], who reported $3.4 \%$ never visited a dentist, $34.5 \%$ visited six months ago, $27.7 \%$ visited a year ago, $13.4 \%$ visited two years ago and $3.4 \%$ visited a dentist more than two years ago from their study among medical student in Egypt. In the present study, it was found out that the association between of last visit to dentist and sex was statistically insignificant $(\mathrm{p}>0.05)$. This result is supported by the submissions of Arun et al., 2010 [15] who reported that no significant difference exist ( $\mathrm{p}>$ 0.05 ) between the last visit to a dentist for medical check-up and sex of medical students.

Findings from this investigation showed that the percentage frequency of last treatment, $19.5 \%$ had extraction as their last treatment, $10.6 \%$ had filling, and $33.3 \%$ had scaling and polishing while $36.6 \%$ had other dental treatment. This finding is partially in line with that of Arun et al., 2010 [15], who reported that 5.0\% never visited a dentist, $26.2 \%$ visited a dentist for check-up, $26.1 \%$ visited for scaling, 3.4\% visited for filling and bracing respectively from their study in India. In our study, it was also observed that the comparison between the last treatment and sex of the respondents was statically insignificant $(p>0.05)$. This 
result agrees with the submission of Arun et al., 2010 [15] who also reported insignificant differences between the last treatment and sex among medical student investigated in India.

In the present study, it was found out that the attitude towards oral health, 93.5\% had positive attitude while $6.5 \%$ had negative attitude towards oral health. This finding concurs with submissions of Vincent et al., 2017 [14] who reported that $87.6 \%$ had positive attitude and $12.4 \%$ had negative attitude towards oral health.

In our study, the comparison between the differences of daily teeth brushing and sex was statistically insignificant $(p>0.05)$. This finding is supported by Arun et al., 2010 [15] who reported that the comparison of frequency of teeth and sex among medical students in India was not significant $(p>0.05)$.

\section{Conclusion}

The knowledge, attitude and oral hygiene practices among medical practitioners are extremely imperative for sensitizing the general public on issues about how to care for and manage oral health conditions. This study revealed immanent overview of oral health knowledge, attitude and practices among medical practitioners in Delta State, Nigeria. It is concluded that oral hygiene knowledge among healthcare providers practicing in Delta State is considerably substantial. This is expected to have a positive impact on the knowledge, attitude and oral hygiene practices of the populace.

\section{Recommendation}

We recommend that further studies should be carried out to assess the knowledge, attitude and practices of oral health among medical practitioners with a different methodology.

\section{Conflicts of Interest}

The authors declare no conflicts of interest regarding the publication of this paper.

\section{References}

[1] Braimoh, O.B. and Owoturo, E.O. (2016) Oral Health Knowledge, Attitude and Behavior of Medical, Pharmacy and Nursing Students at the University of Port-Harcourt, Nigeria Oral Health Knowledge, Attitude and Behavior of Medical, Pharmacy and Nursing Students at the University of Port-Harcourt, Nigeria. Journal of Oral Research and Review, 12, 45-51.

[2] Petersen, P.E. (2003) The World Oral Health Report 2003: Continuous Improvement of Oral Health in the 21st Century-The Approach of the WHO Global Oral Health Programme. Community Dentistry and Oral Epidemiology, 31, 3-23. https://doi.org/10.1046/j..2003.com122.x

[3] Watt, R.G. (2005) Strategies and Approaches in Oral Disease Prevention and Health Promotion. Bulletin of the World Health Organization, 83, 711-718. 
[4] Philipp, S. and Aryan, N. (2017) Assessment of Current Oral Health Knowledge Attitude and Oral Hygiene Practices among 12-Year Old School Children and Patients Attending the Dental Facility at Vezo Hospital in the Rural Village of Andavadoaka, Madagascar. A Pilot Study. Bachelor Thesis, Malmo University, Malmo.

[5] Sharda, A.J. and Shetty, S. (2010) A Comparative Study of Oral Health Knowledge, Attitude and Behaviour of Non-Medical, Para-Medical and Medical Students in Udaipur City, Rajasthan, India. International Journal of Dental Hygiene, 8, 101-109. https://doi.org/10.1111/j.1601-5037.2009.00393.x

[6] Marmot, M. and Bell, R. (2011) Social Determinants and Dental Health. Advances in Dental Research, 23, 201-206. https://doi.org/10.1177/0022034511402079

[7] Paik, D.I., Monn, H.S., Horowitz, A.M., Gitt, H.C., Jeong, K.L. and Suh, S.S. (1994) Knowledge of Oral Practice Related to Caries Prevention among Koreans. Journal of Public Health Dentistry, 54, 205-210. https://doi.org/10.1111/j.1752-7325.1994.tb01216.x

[8] Woolgrove, J., Cumberbatch, G. and Gelbier, S. (1987) Understanding Dental Attendance Behavior. Community Dental Health, 4, 215-221.

[9] Puvvadi, G., Naveen, K., Purvi, M.P., Rashmi, R. and Syeda, N.M. (2016) Enamel Hypoplasia and Dental Caries. Annals of Tropical Medicine and Public Health, 9 , 90-91. https://doi.org/10.4103/1755-6783.177374

[10] Raghdah, O.M. and Ola, M.O. (2016) Assessment of Oral Health Knowledge, Attitude and Practices among Medical Students of Taibah University in Madinah, KSA. British Journal of Medicine \& Medical Research, 18,1-10.

[11] Sede, M.A. and Ehizele, A.O. (2015) Oral Hygiene and Diabetics: Nigeria Medical and Dental Caregivers' Perspective. Annals of African Medicine, 14, 193-199.

[12] Elijah, O.O., Taiwo, O., Micheal, A, Stephen, T.A, Kehinde, U. and Adedotun, A. (2017) Knowledge and Awareness of Medical Doctors, Medical Students and Nurses about Dentistry in Nigeria. Pan African Medical Journal, 23, 172.

[13] Akpata, E.S. (2004) Oral Health in Nigeria. International Dental Journal, 53, 361-365. https://doi.org/10.1111/j.1875-595X.2004.tb00012.x

[14] Vincent, Y.A., Sunny, A.O., Osamwonyi, O. and Eromosele, O. (2017) Knowledge, Attitude towards and Practice of Oral Hygiene among Antenatal Clinic Attendees in Public Secondary Health Facilities in Benin City, Nigeria. Nigerian Health Journal, 17, 1-11.

[15] Arun, K.P.P., Shankar, S., Sowmya, J. and Pviyaa, C.V. (2010) Oral Health Knowledge, Attitude, and Practice of School Students of KSR Matriculation School, Thiruchengale. Journal of Indian Academy of Dental Specialists, 1, 4-11.

[16] Sharda, A.J. and Shetty, S. (2008) A Comparative Study of Oral Health Knowledge, Attitude and Behaviour of Fist and Final Year Dental Students of Udaipur City, Rajastan. Journal of Oral Health Community Dentistry, 2, 46-54. 